\title{
A hindcast simulation of Arctic and Antarctic sea ice variability, 1955-2001
}

\author{
Thierry Fichefet, Hugues Goosse \\ \& Miguel Angel Morales Maqueda
}

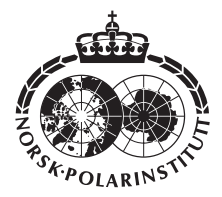

A hindcast simulation of the Arctic and Antarctic sea ice variability during 1955-2001 has been performed with a global, coarse resolution ice-ocean model driven by the National Centers for Environmental Prediction/National Center for Atmospheric Research reanalysis daily surface air temperatures and winds. Both the mean state and variability of the ice packs over the satellite observing period are reasonably well reproduced by the model. Over the 47-year period, the simulated ice area (defined as the total ice-covered oceanic area) in each hemisphere experiences large decadal variability together with a decreasing trend of $\sim 1 \%$ per decade. In the Southern Hemisphere, this trend is mostly caused by an abrupt retreat of the ice cover during the second half of the 1970s and the beginning of the 1980s. The modelled ice volume also exhibits pronounced decadal variability, especially in the Northern Hemisphere. Besides these fluctuations, we detected a downward trend in Arctic ice volume of $1.8 \%$ per decade and an upward trend in Antarctic ice volume of $1.5 \%$ per decade. However, caution must be exercised when interpreting these trends because of the shortness of the simulation and the strong decadal variations. Furthermore, sensitivity experiments have revealed that the trend in Antarctic ice volume is model-dependent.

T. Fichefet \& H. Goosse, Institut d'Astronomie et de Géophysique Georges Lemaître, Université Catholique de Louvain, Chemin du Cyclotron 2,B-1348 Louvain-la-Neuve, Belgium, fichefet@astr.ucl.ac.be; M. A. Morales Maqueda, Potsdam-Institut für Klimafolgenforschung, Telegrafenberg C4, Postfach 601203, D14412 Potsdam, Germany.

Microwave-derived time series of sea ice concentration (the percentage of ice-covered oceanic area) are now among the longest continuous satellite-derived geophysical records, spanning about 25 years. Analyses of these records indicate that the ice area in the Northern Hemisphere (Southern Hemisphere) has shrunk (increased) at an annual mean rate of $\sim 3 \%(\sim 1.5 \%)$ per decade with strong interannual variability since the late 1970s (Bjørgo et al. 1997; Cavalieri et al. 1997; Parkinson et al. 1999; Comiso \& Steffen 2001).

Regarding the longer-term variability, Vinje's study (2001), based on in situ data collected in the
Nordic seas, suggests that the extent of ice in this region during April has undergone a reduction of $\sim 33 \%$ over the past 135 years against a background of pronounced decadal variations. Analysis of another historical data set covering the whole Arctic (updated from Chapman \& Walsh 1993) has revealed that the spring and summer decreases (which are largely responsible for the overall negative trend in Arctic sea ice area during the satellite observing era [Parkinson et al. 1999]) were present during the entire second half of the 20th century and that there has been only a slight and uncertain downward trend in autumn 
and winter since about 1970 (Folland et al. 2001). As for the Antarctic, de la Mare (1997) inferred from whaling records that the summer sea ice edge has moved southwards by $2.8^{\circ}$ of latitude between the mid-1950s and the early 1970 s. This suggests a decline in the area covered by sea ice of some $25 \%$. The indirect nature of the reconstruction, however, makes this conclusion very uncertain (Ackley et al. 2003).

Another important variable characterizing the state of a sea ice pack is its volume, which can be determined from the ice thickness distribution. Our knowledge of sea ice thickness in the Northern Hemisphere (NH) comes mainly from upward sonar profiling by submarines. Rothrock et al. (1999) compared ice draft data acquired by the Scientific Ice Expeditions (SCICEX) programme in 1993, 1996 and 1997 with data from six cruises during the period 1958-1976. They found a decrease in the mean ice draft at the end of the melt season of about $1.3 \mathrm{~m}$ (i.e. $40 \%$ ) in most of the deep-water areas of the Arctic Ocean. Comparing data from single cruises in 1996 and 1976 from Fram Strait to the North Pole, Wadhams \& Davis (2000) reported a strikingly similar reduction in ice draft. In contrast, ice draft data collected during six submarine cruises from Alaska to the North Pole in 1991-97 exhibit almost no change (Winsor 2001). From nine cruises from 1976 through 1994 on the Alaska-to-North Pole section, Tucker et al. (2001) found an abrupt thinning between the mid-1980s and early 1990s. No similar trend was observed, however, near the North Pole. Very recently, a detailed analysis of submarine and modelled ice thicknesses (Holloway \& Sou 2002) has demonstrated that ice motion and high interannual variability make inference of trends from sonar transect data ambiguous. Thus, the available sonar data are insufficient to resolve the variability of the Arctic ice thickness. The situation is even worse in the Southern Hemisphere (SH). So far there have been very few systematic measurements of sea ice thickness in the Southern Ocean and the available records are rather short (e.g. Harms et al. 2001), to the point that the broad spatial and seasonal climatology of Antarctic ice thickness is not well known.

In the present work, a global, coarse resolution ice-ocean model is used to document the variability of the Arctic and Antarctic sea ice during the 47-yearperiod 1955-2001. Daily data of surface air temperature and wind are utilized to produce the year-to-year variations of the ice packs. We focus on analysing the simulated variability of the ice area and volume in both hemispheres. We also evaluate the model performance by comparing ice area anomalies from the last two decades of this hindcast simulation with those derived from satellite measurements. Experiments of this type have been carried out with regional models of the Arctic or Antarctic sea ice-ocean system (e.g. Polyakov \& Johnson 2000; Zhang et al. 2000; Beckmann \& Timmermann 2001; Holloway \& Sou 2002). However, to our knowledge, this is the first time that an ice-ocean model designed for climate studies is utilized for investigating the changes of both the Arctic and Antarctic ice covers in the recent past.

\section{The model, forcing and experimental design}

The model used here is based on that of Goosse et al. (2000) and Fichefet et al. (2003). It is made up of a primitive-equation, free-surface ocean general circulation model coupled to a thermodynamic-dynamic sea ice model with viscous-plastic rheology. The horizontal resolution is $1.5^{\circ} \times 1.5^{\circ}$, and there are 30 unequally spaced vertical levels in the ocean.

The following modifications have been made to the original model. First, a truncated elliptical yield curve and the so-called replacement closure (e.g. Geiger et al. 1998) have been introduced in the formulation of the ice rheology to prevent any tensile stress and to guarantee energy conservation. Second, a more computationally efficient numerical method for solving the ice momentum equation (Zhang \& Hibler 1997) has been implemented. Third, in Fichefet et al. (2003), an ad hoc redistribution of the heat flux through open water was applied to ensure that thermodynamic closure of leads did not occur. This artefact has been removed. The model now includes a physically-based formulation of the opening of leads by shearing deformation (Stern et al. 1995) together with a parameterization of the collection thickness of ice in leads based on that of Biggs et al. (2000).

The model is driven by daily surface air temperatures and winds from the National Centers for Environmental Prediction/National Center for Atmospheric Research (NCEP/NCAR) reanalysis project for the period 1948-2001 (Kalnay et 
al. 1996). The NCEP/NCAR reanalysis data set is the longest global gridded atmospheric data set available today. Unfortunately, it contains a number of inaccuracies, artificial climate trends and even errors (e.g. Hines et al. 2000; Kistler et al. 2001) that must be borne in mind when interpreting the results of our simulation. The other atmospheric input fields consist of climatological monthly surface relative humidities (Trenberth et al. 1989), cloud fractions (Berliand \& Strokina 1980) and precipitation rates (Xie \& Arkin 1996).

The surface fluxes of heat and momentum are determined from these data by using empirical parameterizations (see Fichefet et al. 2003 for details). Evaporation/sublimation is derived from the turbulent flux of latent heat. The freshwater inflows from the largest rivers are prescribed according to the monthly climatology of Grabs et al. (1996). For the smaller rivers, the annual run-off values of Baumgartner \& Reichel (1975) are employed. In addition, a relaxation towards observed annual mean salinities (Levitus 1982) is applied in the $10 \mathrm{~m}$ thick surface grid box with a time constant of 2 months.

The simulation started from a quasiequilibrium state obtained under a monthly climatological forcing built from the above-mentioned data fields. The model was integrated over three 54-year cycles driven by forcing fields from 1948 to 2001. The results discussed below are those from the third cycle. The first 7 years of this cycle are excluded from the analysis because sensitivity experiments to initial conditions showed that the ice characteristics during these years were notably affected by the forcing jump that occurred at the beginning of each cycle and because of the poor quality of the NCEP/NCAR reanalysis data during this period (Kistler et al. 2001).

\section{Results}

Table 1 indicates that the model does fairly well in simulating the mean seasonal cycle of the sea ice area in both hemispheres. Regarding the modelled ice volume, it oscillates in the $\mathrm{NH}$ between a maximum of $29.8 \times 10^{3} \mathrm{~km}^{3}$ in May and a minimum of $15.1 \times 10^{3} \mathrm{~km}^{3}$ in September, on average; it oscillates in the $\mathrm{SH}$ between a maximum of $12.2 \times 10^{3} \mathrm{~km}^{3}$ in October and a minimum of $1.6 \times 10^{3} \mathrm{~km}^{3}$ in February, on average.

The time series of the monthly ice area anomalies produced by the model in both hemispheres are illustrated in Fig. 1. Also shown in this figure are the monthly ice area anomalies derived from passive microwave measurements by using the Bootstrap algorithm (Comiso 2002). The simulated and observed anomalies were obtained by taking the monthly value for each individual month and subtracting the average value for that month over the period during which satellite data are available (November 1978-September 2001). The marked interannual variability seen in the data is relatively well captured by the model. In particular, thanks to the forcing, the model is capable of simulating the transition from a negative anomaly in Arctic ice area in 1995 to a very large positive one in 1996. The abnormally low Antarctic ice areal coverage observed during the second half of 1979 and the first half of 1980 as well as the strong positive and negative anomalies in maximum Antarctic ice area recorded in 1985 and 1986 are also well reproduced. However, one can see that the model significantly underestimates the Arctic ice area during 1979-1981. According to Tartinville et al. (2002), this feature would mostly result from a warm bias in the NCEP/NCAR surface air temperatures during this period in the Beaufort and Laptev seas and in Baffin Bay. In addition to this problem, the model has a tendency to exaggerate the negative ice area

Table 1. Simulated and observed seasonal maximum and minimum sea ice areas in the Northern and Southern hemispheres averaged over the years 1978-2001. The observed values were derived from passive microwave measurements by applying the Bootstrap algorithm (Comiso 2002).

\begin{tabular}{lcccc}
\hline & \multicolumn{2}{c}{ NH sea ice area } & \multicolumn{2}{c}{ SH sea ice area } \\
& March & September & February & September \\
\hline Model & $14.1 \times 10^{6} \mathrm{~km}^{2}$ & $6.5 \times 10^{6} \mathrm{~km}^{2}$ & $1.4 \times 10^{6} \mathrm{~km}^{2}$ & $16.1 \times 10^{6} \mathrm{~km}^{2}$ \\
Observations & $14.2 \times 10^{6} \mathrm{~km}^{2}$ & $6.2 \times 10^{6} \mathrm{~km}^{2}$ & $2.2 \times 10^{6} \mathrm{~km}^{2}$ & $15.8 \times 10^{6} \mathrm{~km}^{2}$ \\
\hline
\end{tabular}




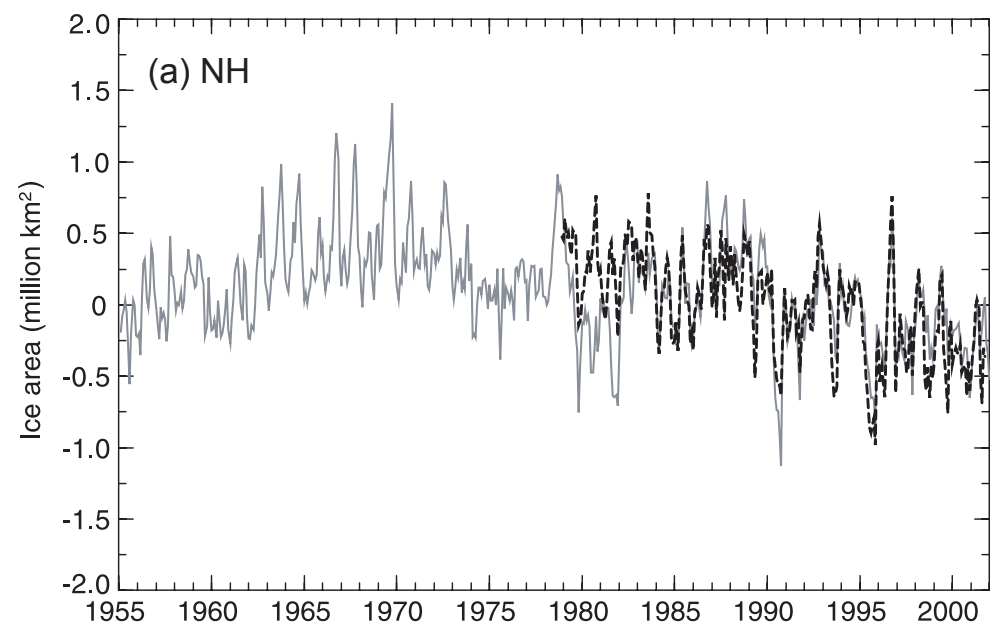

Fig. 1. Time series of monthly ice area anomaly as simulated by the model (grey line) and as observed (dashed black line) for (a) the Northern Hemisphere and (b) the Southern Hemisphere.

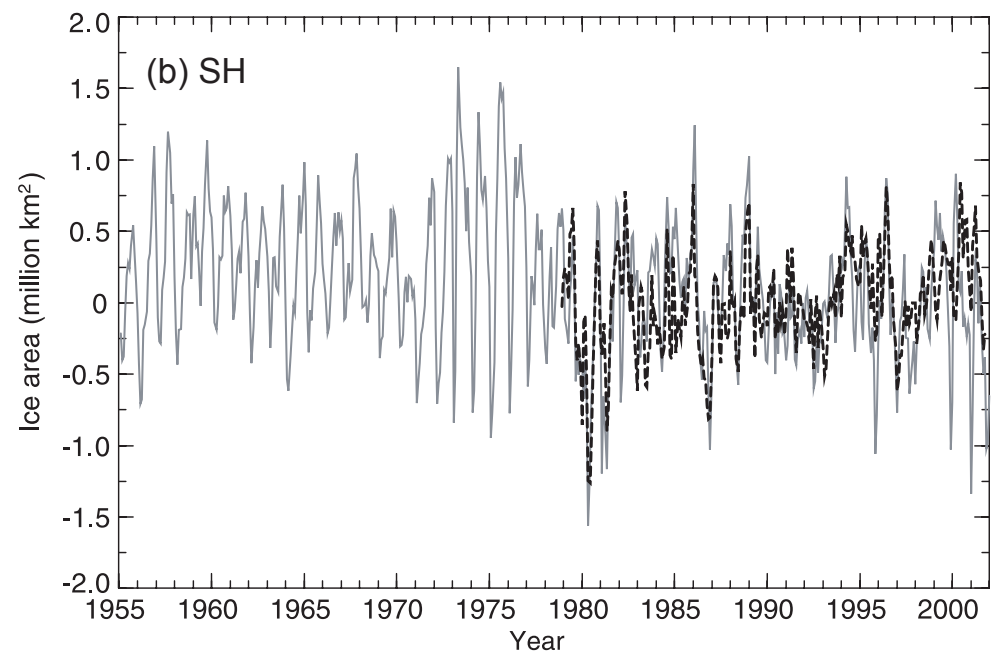

anomalies observed since 1995 in the SH. Despite these shortcomings, the correlation between the simulated and observed time series is 0.75 in the $\mathrm{NH}$ and 0.56 in the $\mathrm{SH}$. On the other hand, the standard deviation of the modelled anomalies over the 22.9-year period of satellite data is $0.33 \times 10^{6} \mathrm{~km}^{2}$ in the NH and $0.44 \times 10^{6} \mathrm{~km}^{2}$ in the $\mathrm{SH}$. These values are consistent with the observed ones $\left(0.36 \times 10^{6} \mathrm{~km}^{2}\right.$ and $0.35 \times 10^{6} \mathrm{~km}^{2}$, respectively), although slightly overestimated in the $\mathrm{SH}$. At least two factors might be responsible for the weaker correlation noticed in the SH: (1) the lower accuracy of the NCEP/NCAR reanalysis data in this hemisphere (Kistler et al. 2001) and (2) the more important role played in the $\mathrm{SH}$ by the deep ocean (which is not restored towards observations in our simulation and thus can depart signif- icantly from reality) in controlling the variability of the sea ice cover. A least squares regression analysis of the model results reveals a decrease of $13650 \pm 2900 \mathrm{~km}^{2} \mathrm{yr}^{-1}$ in Arctic ice area between November 1978 and September 2001. By contrast, no statistically significant trend in Antarctic ice area is detected. As for the Bootstrap data, they show an overall decreasing trend of $32500 \pm 2600 \mathrm{~km}^{2} \mathrm{yr}^{-1}$ in Arctic ice area; they show an overall increasing trend of $15350 \pm 3050$ $\mathrm{km}^{2} \mathrm{yr}^{-1}$ in the Antarctic ice area. It should be noted that the agreement between the simulated and observed trends improves substantially if one excludes from the analysis the years for which we have identified systematic problems (see above). Furthermore, one should mention that there are substantial differences in the satellite-derived sea 
Fig. 2. Time series of monthly ice volume anomaly as simulated by the model for (a) the Northern Hemisphere and (b) the Southern Hemisphere.
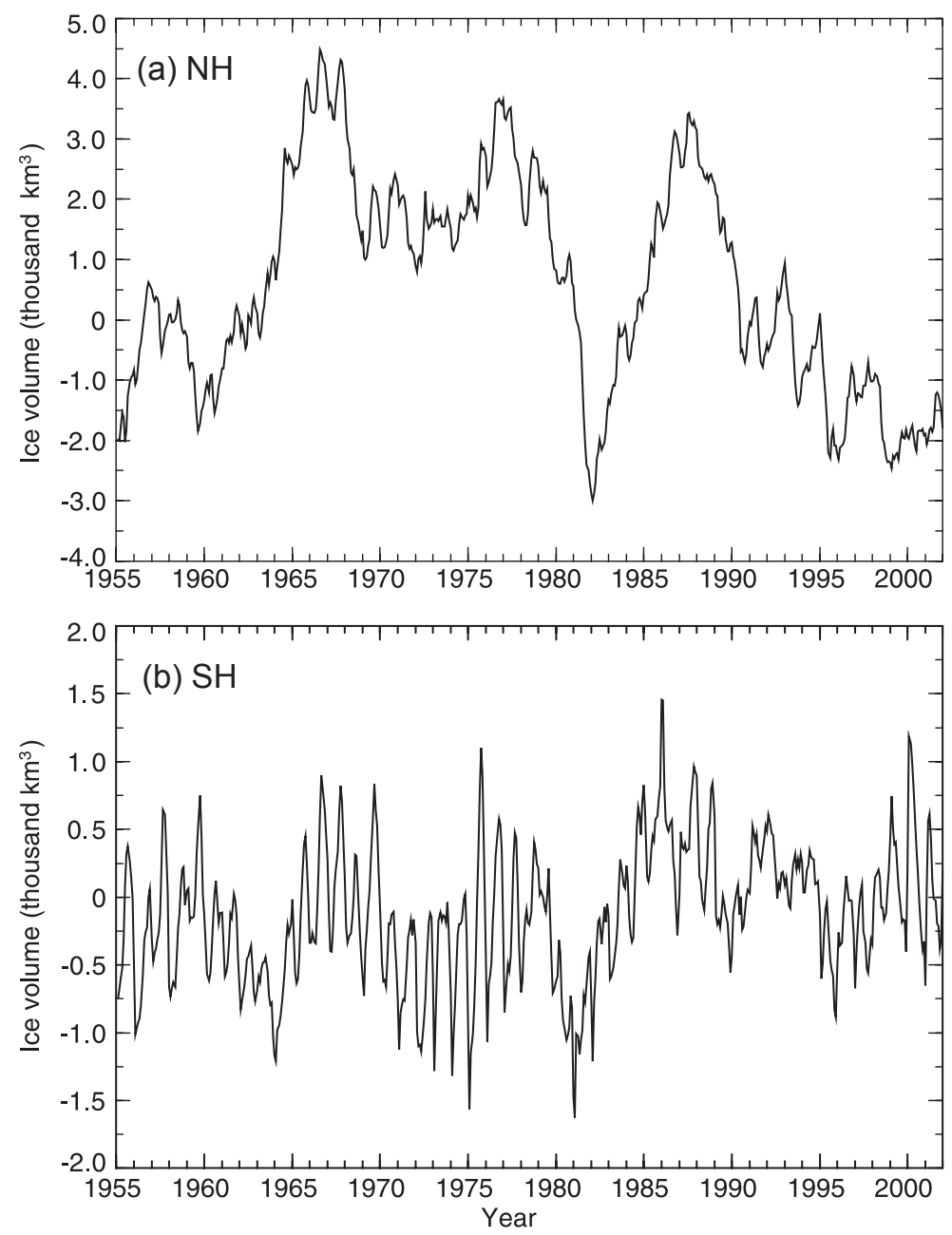

ice areas depending on which algorithm is used to retrieve the ice compactness from the passive microwave data (e.g. Comiso et al. 1997; Markus \& Cavalieri 2000). So, the model might actually do a better job than the comparison with the Bootstrap data suggests.

Over the period 1955-2001, the simulated ice area decreases by $8300 \pm 1000 \mathrm{~km}^{2} \mathrm{yr}^{-1}(0.8 \%$ per decade) in the NH and by $9200 \pm 1500 \mathrm{~km}^{2} \mathrm{yr}^{-1}$ ( $0.9 \%$ per decade) in the SH. Superimposed on these trends are pronounced decadal variations. In the $\mathrm{SH}$, the overall negative trend is mainly due to an abrupt decline in ice area taking place during the second half of the 1970s and the beginning of the 1980s. Actually, the mean ice area from 1982 to 2001 (after the decline) is $0.3 \times 10^{6} \mathrm{~km}^{2}$ lower than that from 1955 to 1976 (before the decline).
This shrinkage is somewhat weaker than the one obtained by Fichefet et al. $(2003)\left(0.5 \times 10^{6} \mathrm{~km}^{2}\right)$ with an earlier version of the model that runs over the period 1958-1999. One cannot rule out the possibility that the modelled decline is caused, at least partly, by a change in the observing systems utilized in the NCEP/NCAR reanalysis. Such a change took place in 1979 when the global operational use of satellite soundings was introduced (Kistler et al. 2001). However, it is noteworthy that the computed monthly ice area anomalies compare favourably with the observed ones during the last two months of 1978 (see Fig. 1). Furthermore, there is some observational evidence that the Antarctic sea ice cover was more extensive in the mid-1970s than during recent decades (e.g. Folland et al. 2001). According to 
Fichefet et al. (2003), this retreat of the ice pack would be partly attributable to the strong weakening of the Antarctic semi-annual oscillation observed since the mid-to-late 1970s in the real atmosphere and also present in the NCEP/NCAR reanalysis (e.g. Van den Broecke 1998).

Figure 2 displays the monthly ice volume anomalies simulated by the model in both hemispheres. As in Fig. 1, the anomalies are relative to November 1978-September 2001. In the model $\mathrm{NH}$, the ice volume experiences strong decadal variability, with maxima around the years 1956, 1966, 1977 and 1987. Large negative anomalies are visible in the early 1980 s and since the mid1990s. Over the entire period, there is a decreasing trend of $40.0 \pm 5.2 \mathrm{~km}^{3} \mathrm{yr}^{-1}$ (1.8\% per decade). This figure must, however, be taken with caution because of the relative shortness of the time series and the high amplitude decadal fluctuations. All these results are consistent with those from other modelling studies (e.g. Hilmer \& Lemke 2000; Polyakov \& Johnson 2000; Zhang et al. 2000; Holloway \& Sou 2002; Tartinville et al. 2002). From Fig. 2 it can be seen that the modelled Antarctic ice volume also exhibits decadal variability. However, the peak-to-trough changes are generally much weaker than the Arctic ones. In addition to these oscillations, there is an overall increase in ice volume of $10.5 \pm 1.5 \mathrm{~km}^{3} \mathrm{yr}^{-1}(1.5 \%$ per decade). This upward trend is mainly a consequence of the enhanced ice volumes produced by the model from the mid-1980s onwards. This feature was not present in the simulation made by Fichefet et al. (2003). Sensitivity experiments performed with the current version of the model have revealed that its occurrence depends on the formulation utilized for lead processes. In particular, the use of a parameterization for the collection thickness of new ice in leads that includes the effect of surface wind (Biggs et al. 2000) seems to be of crucial importance. This will be explored more thoroughly in a forthcoming paper.

\section{Conclusion}

A hindcast simulation has been conducted with a global, coarse resolution ice-ocean model forced with the NCEP/NCAR reanalysis daily surface air temperatures and winds in order to document the variability of the Arctic and Antarctic sea ice covers over the period 1955-2001. We stress that this simulation did not include the potential con- tribution from the hydrological cycle variability to the changes of sea ice on interannual or longer time scales.

The model does reasonably well in reproducing the mean state and variability of the Arctic and Antarctic sea ice areas over the satellite observing era, and this with the same set of parameter values for both hemispheres. Several deficiencies were identified, however, such as too low ice areas in the NH during 1979-1981, too large negative ice area anomalies in the SH since 1995, and too weak and too thin an ice cover in the western Weddell Sea (see Fichefet et al. 2003). Most of them were partly attributed to inaccuracies in the atmospheric forcing fields.

The simulation revealed decadal variations in ice area along with downward trends of about $1 \%$ per decade in both hemispheres over the period 1955-2001. In the $\mathrm{SH}$, this trend mainly results from a mean loss of ice cover of $0.3 \times 10^{6} \mathrm{~km}^{2}$ during the second half of the 1970s and the beginning of the 1980s. The marked weakening of the Antarctic semi-annual oscillation observed since the mid-to-late 1970s in the real atmosphere and captured by the NCEP/NCAR reanalysis seem to contribute significantly to this feature. Nevertheless, part of the modelled decrease in ice area might be spurious and caused by the introduction in the NCEP/NCAR reanalysis of satellite sounding data in 1979.

The computed ice volume also exhibits large decadal variability in both hemispheres. However, the amplitude of the fluctuations appears much higher in the $\mathrm{NH}$ than in the $\mathrm{SH}$. This is due to the fact that most of the Antarctic ice melts away during summertime, while a large part of the Arctic ice cover survives the summer melt, thus providing a memory at longer time scales. Of particular interest in the $\mathrm{NH}$ are the very low values of ice volume simulated in the early 1980s and from the mid-1990s onwards. Over the period 1955-2001, the ice volume decreases by $1.8 \%$ per decade in the model $\mathrm{NH}$ and increases by $1.5 \%$ per decade in the model $\mathrm{SH}$. However, caution must be exercised when interpreting these trends because of the shortness of the time series and the strong decadal variations. Furthermore, we have shown that the $\mathrm{SH}$ trend is highly dependent on the type of lead parameterization utilized. 
Acknowledgements.-We wish to thank the two anonymous referees for their careful reading of the manuscript and constructive criticism. The NCEP/NCAR reanalysis data were provided by the National Oceanic and Atmospheric Administration/Cooperative Institute for Research in Environmental Sciences Climate Diagnostics Center, Boulder, from their internet site at www.cdc.noaa.gov. The Bootstrap sea ice areas were obtained through the National Snow and Ice Data Center, University of Colorado, Boulder. T. Fichefet is Research Associate with the Belgian National Fund for Scientific Research. This study was carried out as part of the Second Multiannual Scientific Support Plan for a Sustainable Development Policy (Belgian State, Prime Minister's Services, Federal Office for Scientific, Technical, and Cultural Affairs, contracts EV/10/7D and EV/10/9A), the concerted research action 097/02-208 (French Community of Belgium, Department of Education, Research, and Formation), the FRFC project 2.4556.99 (Belgian National Fund for Scientific Research), and the French project of operational oceanography MERCATOR. Support from each of these is gratefully acknowledged.

\section{References}

Ackley, S., Wadhams, P., Comiso, J. C. \& Worby A. P. 2003: Decadal decrease of Antarctic sea ice extent inferred from whaling records revisited on the basis of historical and modern sea ice records. Polar Research 22, 19-25.

Baumgartner, A. \& Reichel, E. 1975: The world water balance. New York: Elsevier.

Beckmann, A. \& Timmermann, R. 2001: Circumpolar influences on the Weddell Sea: indication of an Antarctic circumpolar coastal wave. J. Clim. 14, 3785-3792.

Berliand, M. E. \& Strokina, T. G. 1980: Global distribution of the total amount of clouds. Leningrad: Hydrometeorological.

Biggs, N. R. T., Maqueda, M. A. M. \& Willmott, A. J. 2000: Polynya flux model solutions incorporating a parameterization for the consolidated new ice. J. Fluid Mech. 408, 179-204.

Bjørgo, E., Johannessen, O. M. \& Miles, M. W. 1997: Analysis of merged SMMR-SSMI time series of Arctic and Antarctic sea ice parameters 1978-1995. Geophys. Res. Lett. 24, 413-416.

Cavalieri, D. J., Gloersen, P., Parkinson, C. L., Comiso, J. C. \& Zwally, H. J. 1997: Observed hemispheric asymmetry in global sea ice changes. Science 278, 1104-1106.

Chapman, W. L. \& Walsh, J. E. 1993: Recent variations of sea ice and air temperature in high latitudes. Bull. Am. Meteorol. Soc. 74, 33-47.

Comiso, J. C. 2002: Bootstrap sea ice concentrations from Nimbus-7 SMMR and DMSP SSM/I. Boulder: National Snow and Ice Data Center. Digital media.

Comiso, J. C., Cavalieri, D. J., Parkinson, C. L. \& Gloersen, P. 1997: Passive microwave algorithms for sea ice concentration: a comparison of two techniques. Remote Sens. Environ. 60, 357-384.

Comiso, J. C. \& Steffen, J. 2001: Studies of Antarctic sea ice concentrations from satellite data and their applications. $J$. Geophys. Res. 106(C12), 31361-31385.

de la Mare, W. K. 1997: Abrupt mid-twentieth-century decline in Antarctic sea-ice extent from whaling records. Nature 389, 57-60.

Fichefet, T., Tartinville, B. \& Goosse, H. 2003: Antarctic sea ice variability during 1958-1999: a simulation with a global ice-ocean model. J. Geophys. Res. 108(C3), 3103.

Folland, C. K., Karl, T. K., Christy, J. R., Clarke, R. A., Gruza, G. V., Jouzel, J., Mann, M. E., Oerlemans, J., Salinger, M. J. \& Wang, S.-W. 2001: Observed climate variability and change. In J. T. Houghton et al. (eds.): Climate change 2001: the scientific basis. Contribution of Working Group I to the third assessment report of the Intergovernmental Panel on Climate Change. Pp. 99-181. Cambridge: Cambridge University Press.

Geiger, A. G., Hibler, W. D. III \& Ackley, S. 1998: Largescale sea ice drift and deformation: comparison between models and observations in the western Weddell Sea during 1992. J. Geophys. Res. 103(C10), 21 893-21913.

Goosse, H., Campin, J.-M., Deleersnijder, E., Fichefet, T., Mathieu, P.-P., Morales Maqueda, M. A. \& Tartinville, B. 2000: Description of the CLIO model, Version 3.0. Institut d'Astronomie et de Géophysique Georges Lemaître Scientific Report 2000/3. Université Catholique de Louvain, Louvain-la-Neuve, Belgium.

Grabs, W., De Crouet, T. \& Pauler, J. 1996: Freshwater fluxes from continents into the world oceans based on the data of the global runoff data base. Global Runoff Data Centre Report 10. Koblenz.

Harms, S., Fahrbach, E. \& Strass, V. H. 2001: Sea ice transports in the Weddell Sea. J. Geophys. Res. 106(C5), 90579073.

Hilmer, S. \& Lemke, P. 2000: On the decrease of Arctic sea ice volume. Geophys. Res. Lett. 27, 3751-3754.

Hines, K. M., Bromwich, D. H. \& Marshal, G. J. 2000: Artificial surface pressure trends in NCEP-NCAR reanalysis over the Southern Ocean and Antarctica. J. Clim. 13, 3940-3952.

Holloway, G. \& Sou, T. 2002: Has Arctic sea ice rapidly thinned? J. Clim. 15, 1691-1701.

Kalnay, E., Kanamitsu, M., Kistler, R., Collins, W., Deaven, D., Gandin, L., Iredell, M., Saha, S., White, G., Woollen, J., Zhu, Y., Chelliah, M., Ebisuzaki, W., Higgins, W., Janowiak, J., Mo, K. C., Ropelewski, C., Wang, J., Leetmaa, A., Reynolds, R., Jenne, R. \& Joseph, D. 1996: The NCEP/ NCAR 40-year reanalysis project. Bull. Am. Meteorol. Soc. 77, 437-470.

Kistler, R., Kalnay, E., Collins, W., Saha, S., White, G., Woollen, J., Chelliah, M., Ebisuzaki, W., Kanamitsu, M., Kousky, V., Van den Dool, H., Jenne, R. \& Fiorino, M. 2001: The NCEP-NCAR 50-year reanalysis: monthly means CD-ROM and documentation. Bull. Am. Meteorol. Soc. 82, 247-267.

Levitus, S. 1982: Climatological atlas of the world ocean. NOAA Prof. Pap. 13. Washington, D.C.

Markus, T. \& Cavalieri, D. J. 2000: An enhancement of the NASA Team sea ice algorithm. IEEE Trans. Geosci. Remote Sens. 38, 1387-1398.

Parkinson, C. L., Cavalieri, D. J., Gloersen, P., Zwally, H. J. \& Comiso, J. C. 1999: Arctic sea ice extents, areas, and trends, 1978-1996. J. Geophys. Res. 104(C9), 20837-20856.

Polyakov, I. V. \& Johnson, M. A. 2000: Arctic decadal and interdecadal variability. Geophys. Res. Lett. 27, 40974100.

Rothrock, D. A., Yu, Y. \& Maykut, G. A. 1999: Thinning of the Arctic sea-ice cover. Geophys. Res. Lett. 26, 3469- 
3472

Stern, H. L., Rothrock, D. A. \& Kwok, R. 1995: Open water production in Arctic sea ice: satellite measurements and model parameterizations. J. Geophys. Res. 100(C10), 20601-20612.

Tartinville, B., Cavanié, A., Ezraty, R. \& Fichefet, T. 2002: Arctic multiyear ice coverage: a model study. Institut d'Astronomie et de Géophysique Georges Lemaître Scientific Report 2002/1. Université Catholique de Louvain, Louvain-la-Neuve, Belgium.

Trenberth, K. E., Olson, J. G. \& Large, W. G. 1989: A global ocean wind stress climatology based on the ECMWF analyses. National Center for Atmospheric Research Technical Note 338+STR. Boulder, CO.

Tucker, W. B. III, Weatherly, J. W., Eppler, D. T., Farmer, L. D. \& Bentley, D. L. 2001: Evidence for rapid thinning of sea ice in the western Arctic Ocean at the end of the 1980s. Geophys. Res. Lett. 28, 2851-2854.

Van den Broecke, M. R. 1998: The semiannual oscillation and Antarctic climate, part 2: recent changes. Antarct. Sci. 10, 184-191.

Vinje, T. 2001: Anomalies and trends of sea-ice extent and atmospheric circulation in the Nordic seas during the period 1864-1998. J. Clim.14, 255-267.

Wadhams, P. \& Davis, N. R. 2000: Further evidence of ice thinning in the Arctic Ocean. Geophys. Res. Lett. 27,39733975.

Winsor, P. 2001: Arctic sea ice thickness remained constant during the 1990s. Geophys. Res. Lett. 28, 1039-1041.

Xie, P. \& Arkin, P. A. 1996: Analyses of global monthly precipitation using gauge observations, satellite estimates and numerical model predictions. J. Clim. 9, 840-858.

Zhang, J. \& Hibler, W. D. III 1997: On an efficient numerical method for modeling sea ice dynamics. J. Geophys. Res. 102(C4), 8691-8702

Zhang, J., Rothrock, D. \& Steele, M. 2000: Recent changes in Arctic sea ice: the interplay between ice dynamics and thermodynamics. J. Clim. 13, 3099-3114. 